\title{
OBRAS PUBLICAS ESTATALES Y COMPETENCIAS URBANISTICAS
}

\author{
por \\ Tomás Quintana López \\ Elena Ferrero Calzada
}

Con frecuencia, la gestión de las competencias de que dispone el Estado, al precisar de un espacio para su desarrollo, puede entrar en colisión con la atribución de responsabilidades que en materia urbanística han propiciado la Constitución y los Estatutos de Autonomía. Recientemente, una sentencia del Tribunal Constitucional, de fecha 13 de mayo de 1986 (BOE de 13 de junio de 1986), ha solucionado una colisión de este tipo materializada en sendos conflictos positivos de competencia acumulados, el número 228/1983 y el número $326 / 1984$, promovidos por el Gobierno Vasco contra el Acuerdo del Consejo de Ministros de 12 de noviembre de 1982, sobre ejecución de obras del Estado en Vitoria, Lemóniz, San Sebastián e Irún, y contra el Acuerdo también del Consejo de Ministros de 14 de noviembre de 1983, por el que se dispone ejecutar el proyecto de obras de construcción de la Comisaría de Policía de Santurce, respectivamente.

Las decisiones del Gobierno de la Nación se apoyan en el artículo 180,2 , de la Ley del Suelo, que, como es sabido, habilita un expediente mediante el que, en casos de urgencia o excepcional interés público, el Consejo de Ministros puede decidir la ejecución de un proyecto de obras, aunque sea disconforme con el planeamiento 
urbanístico vigente en ese momento, a la vez que impone la iniciación de la modificación o revisión del mismo.

Los Acuerdos del Gobierno, a juicio del Ejecutivo Vasco, vulneran el ámbito competencial que a esta Comunidad Autónoma reconoce el artículo 10,31, de su Estatuto de Autonomía, al prever la competencia exclusiva de la Comunidad Autónoma vasca en materia de ordenación del territorio y del litoral, urbanismo y vivienda; declaración estatutaria seguida del Real Decreto 2581/1980, de 20 de noviembre, de traspaso de servicios, por lo que en esta materia la competencia autonómica es total y absoluta, y no es factible ninguna facultad que no pueda ser ejercitada exclusivamente por la Comunidad Autónoma; por todo ello, a los órganos de esta Autonomía, concretamente al Consejo de Gobierno Vasco, debe corresponder la decisión sobre la ejecución de las obras mencionadas en ejercicio de competencias urbanísticas y en aplicación supletoria, al carecer de normativa propia, del Derecho estatal que contiene la Ley del Suelo, específicamente su artículo 180, 2.

El Letrado del Estado, por su parte, sostiene la validez de los Acuerdos del Gobierno sobre la base de los intereses respectivos, a que hace referencia el artículo 137 de la Constitución, que, a su entender, implica la titularidad autonómica de la competencia prevista en el artículo 180, 2, de la Ley del Suelo cuando la colisión se produce entre el planeamiento urbanístico y la utilización del suelo respecto del que concurren razones de urgencia o excepcional interés público comprendidas dentro del ámbito de intereses propios de la Comunidad Autónoma; intereses que también impiden que ésta pueda asumir esta competencia cuando la colisión entre el planeamiento y el acto de uso del suelo surge por razones de urgencia o excepcional interés público conectadas al ámbito de competencias estatales o, lo que es igual, a los intereses generales de la Nación o supracomunitarios.

La solución que el Tribunal Constitucional da a estos conflictos positivos de competencia, apoyando la pretensión del Letrado del Estado, a nuestro entender es acertada, si bien creemos que las razones en que basa su decisión merecen algún comentario. Textualmente, el fundamento tercero señala:

«El artículo 180,2 , de la LS establece una excepción al régimen urbanístico general, que debe interpretarse de acuerdo con la distribución competencial que establece la Constitución con posterioridad a la entrada en vigor de la Ley del Suelo, que es una Ley pre- 
constitucional. Enfocada asi la cuestión es cierto, como dice la representación del Gobierno Vasco, que todas las competencias urbanísticas, incluida la excepcional reconocida en el artículo 180,2 , de la LS, han sido asumidas por la Comunidad Autónoma del País Vasco en virtud del citado artículo 10, 31 EAPV. Lo único que cabe plantearse es si esa asunción es tan exhaustiva que excluye toda posibilidad, incluso en casos excepcionales, de que el Estado pueda ejercer competencias de contenido distinto de la urbanística, pero que requieran para su ejercicio una proyección sobre el suelo de una Comunidad Autónoma. Ahora bien, tal posibilidad no puede ser excluida, porque el Estado no puede verse privado del ejercicio de sus competencias exclusivas por la existencia de una competencia, aunque también sea exclusiva, de una Comunidad Autónoma, según declaró ya la Sentencia de este Tribunal Constitucional número $1 / 1982$, de 28 de enero, pues tal ineficacia equivaldría a la negación de la misma competencia que le atribuye la Constitución. Estos criterios son aplicables a las facultades excepcionales reconocidas por el artículo 180,2 , de la LS. El Estado podrá ejercerlas en cuanto lo haga en uso de una competencia exclusiva a él atribuida y siempre que se den los presupuestos que señala el mismo artículo 180,2 , de la LS, es decir, la urgencia y el excepcional interés público, de forma que sólo acudiendo a lo preceptuado en dicho artículo sea posible el ejercicio de las referidas competencias. Estos criterios son aplicables a los casos aquí examinados. En efecto, la Constitución reconoce al Estado competencias exclusivas en materia de seguridad pública (artículo 149, 1, 29), sin perjuicio de la posibilidad de creación de Policías autónomas, lo que puede llevar consigo la necesidad de edificar Cuarteles o Comisarías de Policía cuyo emplazamiento o localización no puede ajustarse, por los motivos apuntados, a las determinaciones de los planes urbanísticos. También la Constitución atribuye al Estado competencia exclusiva en materia de Aduanas (art. 149, 1, 10) y, en general, respecto a obras públicas de interés general $(149,1,24)$, entre las que hay que incluir, sin duda, las destinadas a permitir el funcionamiento del régimen aduanero que afecta a todo el Estado. El ejercicio de estas competencias puede permitir al Estado ejercitar la facultad extraordinaria que reconoce el artículo 180, 2, de la LS cuando se den los presupuestos de ese precepto».

De lo dicho, claramente se advierte, como lo hizo el voto particu. lar a esta sentencia suscrito por dos Magistrados, que el Tribunal da entrada a la doctrina de las competencias o poderes implícitos, lo que, aun aceptando la decisión que la sentencia mantiene sobre el fondo del asunto, obliga a los Magistrados discrepantes a buscar una vía interpretativa más acorde con el sistema de delimitación de competencias que resulta de la Constitución y de los Estatutos de Autonomía, sin tener que aceptar el principio de que la titulari- 
dad de una determinada competencia faculta para actuar en otros campos respecto de los que no posee competencia alguna, cuando los actos resulten necesarios para el ejercicio de la competencia propia; en su opinión:

«... El problema planteado en el presente conflicto resulta del hecho de que la norma preconstitucional a cuyo amparo actuó el Gobierno para adoptar acuerdos en materia de urbanismo, norma que no ha sido derogada ni sustituida por ninguna otra por el legislador vasco, excepciona por razones de interés público supramunicipal la competencia municipal en la materia. La interpretación de tal norma, atendiendo fundamentalmente a su espíritu y finalidad, según preceptúa la regla del artículo 3,1 , del Código Civil, obliga a entender que la excepción opera en favor del titular de la competencia atinente al interés público en juego, y por eso en favor del Estado. La legitimidad de la actuación estatal resulta así de la norma legal y no de la potencialidad expansiva de las competencias propias, que en ningún caso puede llevar al desconocimiento de las ajenas».

El razonamiento que mantiene el voto particular evita tener que recurrir a la siempre insegura doctrina de las competencias implícitas, llegando por otro camino a resultados idénticos a los que contiene la sentencia. Una interpretación del artículo 180, 2, de la Ley del Suelo, atendiendo a su espíritu y finalidad, permite, en su opinión, al Estado decidir la ejecución de unas obras motivadas por un interés público supramunicipal del que es responsable el Estado. Sin embargo, pese a que el esfuerzo interpretativo es encomiable, en cuanto que legitima las actuaciones estatales controvertidas en una norma cierta -el artículo 180, 2, de la Ley del Suelo-, lo cierto es que conduce a la atribución de una competencia al Estado en una materia que, como el urbanismo, es de la exclusiva responsabilidad autonómica; además, hacer depender los intereses públicos del Estado que precisan para su gestión una norma legal que está a disposición de las Comunidades Autónomas al ser depositarias, en su integridad, de la competencia sobre la ordenación del territorio y urbanismo, es algo difícilmente sostenible. Siguiendo el planteamiento del voto particular, la solución del conflicto hubiera tenido que ser necesariamente otra si el legislador vasco en uso de sus títulos competenciales hubiera derogado o sustituido la norma que, según sus valedores, permitió al Gobierno de la Nación actuar como lo hizo (1).

(1) Es cierto que las Comunidades Autónomas también pueden optar por respetar o incluso aceptar expresamente la intervención del Gobierno cuando se plantee un 
Por todo ello, y por entender que el Estado no puede verse limitado en el ejercicio de unas competencias de que es titular como consecuencia del ejercicio que las Comunidades Autónomas realicen de las suyas en materia de ordenación del territorio y urbanismo, es por lo que hay que buscar un título hábil que permita al Estado hacer uso del suelo, siempre que ello venga impuesto por razones de urgencia o excepcional interés público, sin tener que acudir al Ejecutivo autonómico para que en uso de sus atribuciones decida sobre el ejercicio de unas competencias de que no es titular la Comunidad Autónoma a que pertenece.

El objetivo señalado de nuevo nos pone frente a la doctrina que ha servido al Tribunal Constitucional para fundamentar su decisión. Es cierto que el Alto Tribunal hace en esta sentencia un uso muy comedido de la potencialidad expansiva de las competencias del Estado, circunscribiendo su viabilidad a unos límites muy prudenciales que fija en el fundamento cuarto:

«Téngase en cuenta también, para fijar con más precisión las facultades que el Estado (y, en su caso, la Comunidad Autónoma) pueden asumir, conforme al artículo 180, 2, de la LS, que tales facultades no pueden ser interpretadas como la posibilidad de realizar actos urbanísticos libremente y sin respetar el planeamiento previsto siempre que se den los presupuestos de urgencia y excepcional interés público, ni que la concurrencia de tales requisitos pueda ser estimada discrecionalmente por el Gobierno. Respecto al primer punto conviene recordar que el planeamiento urbanístico forma parte del ordenamiento jurídico al que están sujetos todos los poderes públicos (artículo 9, 1, de la Constitución). El Estado tendrá que conformar en principio los actos que pretenda realizar al planeamiento existente. Sólo cuando esto no resulte posible y el excepcional interés público exija no sólo proceder por vía de urgencia, que exime solicitar previamente la licencia municipal, sino no respetar el planeamiento

conflicto motivado por la disconformidad entre el planeamiento urbanístico y la obra que el Estado, en uso de sus competencias, pretende realizar; éste ha sido el caso de la Comunidad Autónoma madrileña, en cuya Ley 4/1984, de 10 de febrero, artículo 19,2 y 3 , se señala:

«En caso de disconformidad, a que se refiere el número 2 del artículo 180 de la vigente Ley del Suelo, será competente el Consejo de Gobierno de la Comunidad Autónoma para decidir sobre la procedencia de la ejecucion de los proyectos, cuando hayan sido promovidos por órganos o entidades de Derecho público de la Comunidad Autónoma, previo informe del Consejo de Ordenación del Territorio, Medio Ambiente y Vivienda y de la Comisión de Urbanismo y Medio Ambiente.

Cuando los proyectos no hayan sido promovidos por los órganos a que se hace referencia en el párrafo anterior, el Consejo de Ordenación del Territorio, Medio Ambiente y Vivienda informará previamente a la propuesta que el Ministro de Obras Públicas y Urbanismo haya de elevar al Consejo de Ministros, de conformidad con lo que prevé el artículo 180,2 y 3 , de la Ley del Suelo». 
establecido, cabrá apartarse de éste y ordenar la iniciación del procedimiento de revisión o modificación del planeamiento previsto en el mismo artículo 180, 2. Y, naturalmente, los acuerdos que en aplicación de este artículo de la LS adopte el Gobierno son recurribles ante la jurisdicción competente, tanto por el Municipio afectado como por el Gobierno Vasco e incluso por cualquier ciudadano, ya que la legislación urbanística reconoce la acción popular (artículo 235 LS); y a los Tribunales corresponde decidir si se han dado determinados los presupuestos de urgencia y excepcional interés público, y si era necesario, en su caso, apartarse del planeamiento establecido".

Pero también es cierto que el Tribunal acude a la doctrina de los poderes implícitos sin antes haber tratado de fundamentar los Acuerdos del Gobierno que suscitaron los conflictos positivos de competencias en el cuadro competencial que expresamente diseña la propia Constitución. Las competencias implícitas, si bien tienen acogida en nuestro ordenamiento constitucional, su uso exige necesariamente haber agotado con anterioridad todas las posibilidades que ofrece el texto constitucional para delimitar el régimen competencial que éste establece (2), cuestión que intentamos a continuación.

El planeamiento, como técnica al servicio de un urbanismo racionalizador de la utilización del suelo, ha de presidir los distintos destinos de que es susceptible, sin que quepa objetar que su uso obedece al ejercicio de competencias estatales de cualquier otra Administración pública o de simples particulares. Los planes urbanísticos para que verdaderamente sean piezas integradoras de los diferentes usos del suelo, han de dar respuesta a las exigencias derivadas del ejercicio competencial de todas las Administraciones públicas, lo que supone una ineludible labor de coordinación en el momento de su elaboración entre todas las instancias que, bien en uso de sus competencias o bien con su simple actividad, van a in-

(2) Es oportuno recordar a MUÑoz MACHADO cuando afirma: «Sin embargo, ya en nuestra época la doctrina insiste en recordar algo que también entre nosotros deberá tenerse muy en cuenta: no debe pretenderse, ni de lejos, que la teoría de los poderes pueda tener en un sistema como el de la Ley Fundamental de Bonn (o como el de nuestra Constitución) una aplicación y utilidad semejante a las que ha tenido en el federalismo norteamericano porque las bases de partida son radicalmente diversas. En estos modernos sistemas, la distribución de competencias está prácticamente agotada con la técnica de las listas y de las cláusulas generales y es, por tanto, a las presoripciones constitucionales correspondientes a donde hay que acudir para resolver los problemas interpretativos y donde se encontrarán ordinariamente resueltos. No quiere ello decir que la técnica de los poderes implícitos carezca aquí de aplicación, pero desde luego sí que puede afirmarse que deberá ser menos extensa y más matizada». 
cidir en la transformación o utilización del suelo (3). El planteamiento que se acaba de hacer, a nuestro juicio, evita la mayoría de colisiones entre el ejercicio de competencias por el Estado que necesiten de una ubicación física en el suelo y la Comunidad Autónoma titular de la competencia en materia urbanística y, por tanto, responsable de la gestión del territorio de la Comunidad. Pero si ésta ha de ser la situación normal, es imposible que no se den situaciones de urgencia o de excepcional interés público, en cuyo caso no puede quedar paralizada la actuación del Estado en uso de sus competencias por no adecuarse la utilización del suelo que requiere su ejercicio a las determinaciones del planeamiento. La situación que aparece en el caso que se acaba de indicar escapa a la vía que hemos llamado normal de integración de las competencias estatales en la gestión racional del suelo, cuyo responsable final es la Comunidad Autónoma dentro de su territorio; dicha colisión propiciada por la urgencia o el excepcional interés público no es otra cosa que un conflicto entre dos títulos competenciales que hay que resolver a través de las reglas que establece la propia Constitución, en este caso mediante lo previsto en el artículo 149, 3.

El juego de estos títulos competenciales precisará de una coordinación continua entre las Administraciones públicas a la hora de elaborar los instrumentos de planeamiento, de forma que queden integradas en ellas las futuras utilizaciones del suelo, por lo que el Estado, en condiciones normales, no ha de encontrar obstáculo alguno en las determinaciones contenidas en los planes urbanísticos; solamente escapan a esta formulación ordinaria los supuestos de urgencia y excepcional interés público, en este caso del Estado, para realizar ciertos usos del suelo en contradicción con las previsiones urbanísticas. Recurrir para atribuir al Consejo de Ministros la competencia del artículo 180,2, de la Ley del Suelo, a la doctrina de las competencias implícitas, por muchas cautelas de que se rodee, como hace la propia sentencia, supone situar en un primer plano una doctrina con vocación subsidiaria, máxime cuando el constituyente ha previsto una regla de prevalencia en favor del Estado en caso de conflicto con las Comunidades Autónomas, conflicto que en este caso se plantea por la urgencia y la excepcionalidad del interés público de una actuación del Estado difícilmente alcanzable por la vía ordinaria.

(3) Vid. el artículo 4 de la Ley 12/1983, de 14 de octubre, del Proceso Autonómico. 
Los poderes implícitos tienen cabida en nuestro orden constitucional una vez agotadas sin éxito las reglas de distribución de competencias contenidas en la norma fundamental y Estatutos de Autonomía; sin embargo, su aplicación dentro de esas coordenadas no tiene que partir de una situación conflictiva, para eso ya está la cláusula de prevalencia; además, una institucionalización de las competencias implícitas para legitimar actuaciones estatales fuera del marco urbanístico, pese a que su aplicación se rodee de numerosas cautelas, puede contribuir a desnaturalizar la esencia integradora de los planes urbanísticos. Por el contrario, la prevalencia de los títulos estatales sobre los ostentados por las Comunidades Autónomas, según señala el artículo 149, 3, de la Constitución, precisa de una situación conflictiva, cuya existencia habrá de constatarse mediante el control de la efectiva urgencia y la realidad del excepcional interés público. Precisamente, en el juego de la cláusula de prevalencia es donde encuentran sentido las prevenciones que contiene el fundamento cuarto de la sentencia antes transcrito, prevenciones que con indudable acierto han sido detalladas por el Tribunal Constitucional, si bien su función más clara está en determinar la existencia de conflictos debido a la urgencia o el excepcional interés público que justifica acudir a la situación prevalente del Estado como titular de una competencias ordenadas a construir, preservar y reforzar de manera permanente la unidad global del sistema y su cohesión última, por encima de los particularismos territoriales autonómicos (4).

En consecuencia, es necesario que Estado y Comunidades Autónomas coordinen la necesidad de utilizar el territorio por parte de aquél en el ejercicio de sus competencias con las previsiones urbanísticas de los instrumentos de planeamiento a fin de que queden integrados en éstos; solamente en caso de conflicto motivado por las circunstancias tantas veces señaladas, los intereses del Estado legítimamente prevalecerán por imperativos del artículo 149,3 , de la Constitución (5), imponiendo su órgano superior ejecutivo la modificación del planeamiento o su revisión para integrar entre sus determinaciones el proyecto con cuya ejecución surgió el conflicto.

(4) Este es el fundamento, según GARCía DE ENTERRfA, de la regla de prevalencia; vid. su trabajo: $« \mathrm{El}$ ordenamiento estatal y los ordenamientos autonómicos: sistema de relaciones", Organización territorial del Estado (Comunidades Autónomas), volumen I, Instituto de Estudios Fiscales, Madrid, 1984, pág. 151.

(5) Vid. también, en este sentido, Fernández RodŔ́guez: Manual de Derecho urbanistico, Abella, 5: edición, Madrid, 1985, pág. 96. 